\title{
The impact of social deprivation on mortality following acute myocardial infarction, stroke or subarachnoid haemorrhage: A record linkage study
}

\author{
Kymberley Thorne*, John G. Williams, Ashley Akbari and Stephen E. Roberts
}

\begin{abstract}
Background: The impact of social deprivation on mortality following acute myocardial infarction (AMI), stroke and subarachnoid haemorrhage (SAH) is unclear. Our objectives were, firstly, to determine, for each condition, whether there was higher mortality following admission according to social deprivation and secondly, to determine how any higher mortality for deprived groups may be correlated with factors including patient demographics, timing of admission and hospital size.
\end{abstract}

Methods: Routinely collected, linked hospital inpatient, mortality and primary care data were analysed for patients admitted as an emergency to hospitals in Wales between 2004 and 2011 with AMI $(n=30,663)$, stroke $(37,888)$ and SAH (1753). Logistic regression with Bonferroni correction was used to examine, firstly, any significant increases in mortality with social deprivation quintile and, secondly, the influence of patient demographics, timing of admission and hospital characteristics on any higher mortality among the most socially deprived groups.

Results: Mortality was $14.3 \%$ at 30 days for AMI, $21.4 \%$ for stroke and $35.6 \%$ for SAH. Social deprivation was significantly associated with higher mortality for AMI (25\%; $95 \% \mathrm{Cl}=12 \%, 40 \%)$ higher for quintile $\mathrm{V}$ compared with I), stroke (24\%; $14 \%, 34 \%)$, and non-significantly for SAH (32\%; -7\%, $87 \%)$.

The higher mortality at 30 days with increased social deprivation varied significantly according to patient age for AMI patients and time period for SAH. It was also highest for both AMI and stroke patients, although not significantly for female patients, for admissions on weekdays and during autumn months.

Conclusions: We have demonstrated a positive association between social deprivation and higher mortality following emergency admissions for both AMI and stroke. The study findings also suggest that the influence of patient demographics, timing of admission and hospital size on social inequalities in mortality are quite similar for AMI and stroke.

Keywords: Mortality, Social deprivation, Risk factors, Acute myocardial infarction, Stroke, Subarachnoid haemorrhage

\section{Background}

Acute myocardial infarction (AMI), stroke and subarachnoid haemorrhage (SAH) are all associated with high mortality following hospitalisation [1]. Some research suggests that mortality rates are significantly higher for more deprived than more affluent patients following admission for cardiovascular disease [2-6], stroke [3, 7-13] and SAH $[8,14]$. Possible reasons include patient comorbidities, poor diet, obesity and other lifestyle risk factors, as well as differences in health seeking behaviours and

\footnotetext{
* Correspondence: k.thorne@swansea.ac.uk

College of Medicine, Swansea University, Singleton Park, Swansea SA2 8PP, UK
}

inequalities in access to and compliance with treatment and care. However, other studies have reported either no significant association with mortality for cardiovascular diseases [15-17] and stroke [18-20], or that mortality was lower with increased social deprivation for cardiovascular conditions [21, 22] and stroke [23].

There is a lack of evidence for the reasons why social deprivation inequalities in mortality following admission for AMI, stroke or SAH may be affected by factors including patient demographics, timing of admission and the size of the hospital. It is possible that day of the week, year of admission and hospital size could act as 
possible mediators of the relationship between social deprivation and 30 day mortality for AMI, stroke and $\mathrm{SAH}$. If so, we hypothesise that deprived cases would have a worse prognosis if admitted on weekdays and public holidays as any social inequalities in access to urgent investigative and therapeutic services and surgery may be widened by reduced operational levels of services at weekends. Additionally, it has been reported that affluent patients get to hospital sooner following a stroke [9] which may be linked to the admitting hospital's location and size.

In order to explore these possibilities, we investigated associations between social deprivation and mortality following AMI, stroke and SAH in a large population in the UK. The first objective of this study was to determine, for each condition, whether there was higher mortality at 30 days following admission according to social deprivation. Secondly, we determined how any higher mortality for deprived groups may be correlated with factors such as patient demographics, timing of admission and hospital size.

\section{Methods}

\section{Study design}

To address these study objectives, we used systematic record linkage of national inpatient, mortality and primary care data across Wales (population 3 million). All records were held within the Secure Anonymised Information Linkage (SAIL) Databank, which includes the Patient Episode Database for Wales (PEDW) and the Welsh Administrative Register (AR). All records were linked using a unique anonymised linking field (ALF) for each patient based primarily on the patient's National Health Service (NHS) number and secondly, on other anonymised patient identifiers such as date of birth, gender, postcode and first name and surname by applying a probabilistic matching algorithm MACRAL (Matching Algorithm for Consistent Results in Anonymised Linkage). More details on the SAIL databank and the MACRAL methodology can be found in articles by Lyons et al. and Ford et al. to confirm the accuracy of linkage using this method [24, 25].

To identify all deaths that occurred following discharge from hospital as well as in hospital, the inpatient data were systematically linked to death certificate data from the Office for National Statistics (ONS) and the Welsh AR. Linkage was possible for $100 \%$ of patients in our dataset.

To obtain information on comorbidities recorded from primary care consultations as well as inpatient admissions over the previous 5 years, the inpatient data were also linked to SAIL national primary care data. The SAIL databank has access to $40 \%$ of GP practice data in Wales (approximately 1 million records). We also adjusted for whether each patient had a previous GP or inpatient visit been to eliminate any bias during logistic regression modelling.

\section{Ethics statement}

Ethical approval and patient consent for the study data was not required as we were using pseudo-anonymised data. Study approval was obtained instead from the Information Governance Review Panel, which is represented by the National Research Ethics Service, the British Medical Association Ethics Advisor, the Caldicott Guardians and NHS Wales Informatics Service. The linked study data sources we used are publicly available to other researchers.

\section{Inclusion and exclusion criteria}

We selected all emergency admissions to Welsh hospitals where AMI, stroke or SAH were recorded as the principal diagnosis on the discharge record. The International Classification of Diseases tenth revision (ICD-10) codes used for the three conditions were I21, I61-64 and I60 respectively. We included patients aged 18 years or over, admitted between January $1^{\text {st }} 2004$ and December $31^{\text {st }} 2011$ and followed them up for 12 months. Admissions were excluded if they were not emergencies (e.g. elective) or if they occurred within 365 days of a previous admission's discharge date.

\section{Mortality}

Mortality rates at 30 days following the admission were used as the primary outcome measure and at 7 days and 365 days as secondary outcome measures. Thirty day mortality is a common outcome measure in the literature. Mortality was based on all causes of death. We included deaths occurring during the inpatient stay and those occurring following discharge.

\section{Social deprivation}

Social deprivation for the Welsh population was measured using the Welsh Index of Multiple Deprivation (WIMD) 2008 [26], produced by the Welsh Assembly Government. It is an area-based measure consisting of seven separate domains of deprivation: 'income' (23.5\% contribution), 'employment' (23.5\%), 'health' (14\%), 'education' (14\%), 'access to services' (10\%), 'housing' (5\%), 'physical environment' (5\%) and 'community safety' (5\%). It is based on 1896 Lower Super Output Areas (average population $=\sim 1500$ each) and provides a deprivation score which was ranked and assigned to one of five deprivation quintiles ( $\mathrm{I}=$ least deprived and $\mathrm{V}=$ most deprived quintile). 


\section{Risk factors}

We assessed the following key risk factors to determine whether they significantly mediated the relationship between social deprivation and mortality at 30 days following admission, comparing the least and most deprived cases, using the least deprived quintile as the reference group.

\section{Patient demographics}

The patient's age on admission was collected for each case. Age was grouped into " $<65$ years", "65 to 74 years", "75 to 84 years" and " $85+$ years" The patient's gender was also recorded.

\section{Timing of admission}

We investigated any impact of the day of admission on mortality by assigning weekdays (Monday 00:00 to Friday 23:59), weekends (Saturday 00:00 to Sunday 23:59) and public holiday ( 8 per year) with public holidays prioritised over weekdays and weekends in this classification. We also investigated the season of admission (winter = Dec to Feb; spring = Mar to May; summer = Jun to Aug; autumn = Sept to Nov) and grouped year of admission ("20042005", “2006-2008” and "2009-2011”).

\section{Hospital size}

Hospital size at the time of admission was included with the following categories: "Small District General Hospital (DGH) (100-399 beds)", "medium DGH (400-599 beds)", "large DGH (600+ beds)" and "community hospital (less than 100 beds)".

\section{Patient comorbidities}

When investigating mortality, we also adjusted for age group, gender and comorbidities. Specifically, we adjusted for any impact of the following 11 major patient comorbidities recorded in any diagnostic position during the admission, or within the previous 5 years from primary and inpatient care records where available: ischaemic heart disease (I20-I25) or other cardiovascular diseases (I00I15, I26-I52), cerebrovascular disease (I60-I69), other circulatory diseases (I70-I99), malignancies (C00-C97), chronic obstructive pulmonary disease (J40-J44), asthma (J45-J46), diabetes (E10-E14), dementia (F00-F03, F05.1, G30), liver disease (K70-K77) and renal failure (N17N19) [27].

\section{Sample size calculations}

Detecting a $30 \%$ increased risk in adjusted mortality for quintile $\mathrm{V}$ compared to quintile I based on mortality rates of 35, 15 and $20 \%$ for AMI, stroke and SAH respectively and using $80 \%$ power and $5 \%$ significance, would require 1150 AMI cases, 805 stroke cases and 360 $\mathrm{SAH}$ cases in each quintile.

\section{Methods of analysis}

The main study outcome measures were percentage mortality rates and odds of mortality for quintile $\mathrm{V}$ versus quintile I at 30 days following admission for each condition. Secondary outcome measures were mortality rates and odds of mortality at 7 and 365 days.

Logistic regression was undertaken to establish, firstly, any increased odds of mortality associated with social deprivation at 7 and 30 days after admission. Secondly, it was used to establish how any higher mortality for deprived groups may be related to key risk factors including patient demographics, timing of admission and hospital size. To do this, we compared mortality in the least and most deprived quintiles, using the least deprived quintile as the reference category, for each individual strata in the risk factors; patient age group, sex, week day, season and time period of admission and hospital size. Thirdly, logistic regression was used to test for any interaction effects on mortality between social deprivation and, respectively, each of the study risk factors.

All logistic regression analyses adjusted for age, gender and the eleven patient comorbidities. To eliminate possible biases in the determination of patient co-morbidities from primary and secondary care diagnoses over the preceding 5 years, we also adjusted for patients with no previous inpatient admissions or primary care consultations. The logistic regression mortality odds ratios were presented with $95 \%$ confidence intervals. Significance was measured at the conventional $5 \%$ level.

There were no missing data for any factor other than patient gender and social deprivation (WIMD). For gender, one case admitted with AMI was missing. For WIMD, data was not available for the patients who were not normally resident in Wales. This equated to $3.2 \%$ of AMI cases, $2.4 \%$ of stroke cases and $3.1 \%$ of SAH cases.

A Bonferroni correction was applied to account for multiple statistical tests for each condition. Results were displayed in tables to indicate whether they were significant before and after the correction was applied, although the text only refers to results significant after the correction was applied.

\section{Results}

There were 30,663 cases of AMI, 37,888 cases of stroke and 1753 cases of SAH admitted as emergencies between January 2004 and December 2011. The mean age at admission was 70.9 years \pm 13.8 for AMI, 75.7 years \pm 12.7 for stroke and 60.7 years \pm 16.0 for SAH. Males accounted for $60.2 \%, 47.3 \%$ and $36.5 \%$ of cases respectively.

\section{Mortality and social deprivation}

Mortality at 30 days was $14.3 \%$ following admission for AMI, 21.4 \% for stroke and $35.6 \%$ for SAH (see Table 1). Corresponding mortality at 7 days for AMI, stroke and 
Table 1 Admission numbers, mortality rates and adjusted odds ratios at 7, 30 and 365 days following hospitalisation, 2004-2012

\begin{tabular}{|c|c|c|c|c|c|c|c|c|}
\hline Condition & Risk factor & Admissions (n) & 7 days mortality rate & $\begin{array}{l}7 \text { days OR } \\
(95 \% \text { Cl) }\end{array}$ & 30 days mortality rate & $\begin{array}{l}30 \text { days OR } \\
(95 \% \mathrm{Cl})^{\mathrm{b}}\end{array}$ & $\begin{array}{l}365 \text { days } \\
\text { mortality rate }\end{array}$ & $\begin{array}{l}365 \text { days OR } \\
(95 \% \mathrm{Cl})^{\mathrm{b}}\end{array}$ \\
\hline \multirow[t]{15}{*}{ AMI } & All cases & 30,663 & $9.2 \%$ & - & $14.3 \%$ & - & $24.6 \%$ & - \\
\hline & \multicolumn{8}{|l|}{ Age } \\
\hline & $<65 y$ & 9827 & $2.8 \%$ & - & $4.0 \%$ & - & $6.2 \%$ & - \\
\hline & $65-74 y$ & 7088 & $7.4 \%$ & - & $10.6 \%$ & - & $17.2 \%$ & - \\
\hline & $75-84 y$ & 8382 & $12.7 \%$ & - & $19.6 \%$ & - & $34.3 \%$ & - \\
\hline & $85 y+$ & 5366 & $17.7 \%$ & - & $29.5 \%$ & - & $52.8 \%$ & - \\
\hline & \multicolumn{8}{|l|}{ Gender } \\
\hline & Male & 18,456 & $7.7 \%$ & Ref & $11.9 \%$ & Ref & $20.5 \%$ & Ref \\
\hline & Female & 12,206 & $11.4 \%$ & $1.09(1.00,1.18)$ & $17.8 \%$ & $1.07(0.99,1.15)$ & $30.8 \%$ & $1.10(1.03,1.17)$ \\
\hline & \multicolumn{8}{|l|}{ Social deprivation } \\
\hline & I (Least deprived) & 4776 & $8.9 \%$ & Ref & $14.5 \%$ & Ref & $25.3 \%$ & Ref \\
\hline & $\|$ & 5527 & $8.7 \%$ & $1.04(0.90,1.19)$ & $13.4 \%$ & $0.97(0.86,1.09)$ & $23.6 \%$ & $0.98(0.89,1.09)$ \\
\hline & III & 6579 & $9.1 \%$ & $1.11(0.97,1.27)$ & $14.3 \%$ & $1.07(0.96,1.20)$ & $25.4 \%$ & $1.12(1.01,1.23)$ \\
\hline & IV & 6460 & $9.6 \%$ & $1.23(1.07,1.40)$ & $15.0 \%$ & $1.17(1.05,1.31)$ & $25.3 \%$ & $1.13(1.02,1.24)$ \\
\hline & V (Most deprived) & 6342 & $9.9 \%$ & $1.34^{\mathrm{a}}(1.17,1.53)$ & $15.0 \%$ & $1.25^{\mathrm{a}}(1.12,1.40)$ & $25.3 \%$ & $1.20^{\mathrm{a}}(1.08,1.32)$ \\
\hline \multirow[t]{15}{*}{ Stroke } & All cases & 37,888 & $11.6 \%$ & - & $21.4 \%$ & - & $37.7 \%$ & - \\
\hline & \multicolumn{8}{|l|}{ Age } \\
\hline & $<65 y$ & 6779 & $7.9 \%$ & - & $10.9 \%$ & - & $5.9 \%$ & - \\
\hline & $65-74 y$ & 7989 & $9.4 \%$ & - & $14.9 \%$ & - & $25.1 \%$ & - \\
\hline & $75-84 y$ & 13,171 & $11.7 \%$ & - & $21.6 \%$ & - & $39.6 \%$ & - \\
\hline & $85 y+$ & 9949 & $15.7 \%$ & - & $33.4 \%$ & - & $60.4 \%$ & - \\
\hline & \multicolumn{8}{|l|}{ Gender } \\
\hline & Male & 17,936 & $9.8 \%$ & Ref & $17.6 \%$ & Ref & $32.1 \%$ & Ref \\
\hline & Female & 19,952 & $13.1 \%$ & $1.25^{\mathrm{a}}(1.16,1.33)$ & $24.7 \%$ & $1.21^{\mathrm{a}}(1.15,1.3)$ & $42.8 \%$ & $1.23^{\mathrm{a}}(1.17,1.29)$ \\
\hline & \multicolumn{8}{|l|}{ Social deprivation } \\
\hline & I (Least deprived) & 6390 & $11.3 \%$ & Ref & $20.9 \%$ & Ref & $37.2 \%$ & Ref \\
\hline & $\|$ & 6803 & $11.3 \%$ & $1.01(0.91,1.13)$ & $21.7 \%$ & $1.09(1.00,1.19)$ & $39.1 \%$ & $1.13^{\mathrm{a}}(1.05,1.22)$ \\
\hline & III & 8078 & $12.2 \%$ & $1.12(1.01,1.24)$ & $22.2 \%$ & $1.12(1.04,1.22)$ & $38.7 \%$ & $1.12(1.04,1.21)$ \\
\hline & IV & 7817 & $11.3 \%$ & $1.05(0.95,1.17)$ & $20.5 \%$ & $1.06(0.97,1.15)$ & $37.5 \%$ & $1.12(1.04,1.20)$ \\
\hline & V (Most deprived) & 7886 & $11.9 \%$ & $1.17(1.05,1.30)$ & $22.0 \%$ & $1.24^{\mathrm{a}}(1.14,1.34)$ & $37.9 \%$ & $1.23^{\mathrm{a}}(1.15,1.33)$ \\
\hline
\end{tabular}


Table 1 Admission numbers, mortality rates and adjusted odds ratios at 7, 30 and 365 days following hospitalisation, 2004-2012 (Continued)

\begin{tabular}{|c|c|c|c|c|c|c|c|c|}
\hline \multirow[t]{15}{*}{ SAH } & All cases & 1753 & $26.9 \%$ & - & $35.6 \%$ & - & $40.4 \%$ & - \\
\hline & Age & & & & & & & \\
\hline & $<65 y$ & 1043 & $22.5 \%$ & - & $27.0 \%$ & - & $28.9 \%$ & - \\
\hline & $65-74 y$ & 317 & $29.7 \%$ & - & $41.0 \%$ & - & $47.3 \%$ & - \\
\hline & $75-84 y$ & 266 & $34.6 \%$ & - & $54.1 \%$ & - & $62.4 \%$ & - \\
\hline & $85 y+$ & 127 & $40.2 \%$ & - & $53.5 \%$ & - & $70.5 \%$ & - \\
\hline & Gender & & & & & & & \\
\hline & Male & 634 & $26.8 \%$ & Ref & $35.6 \%$ & Ref & $40.5 \%$ & Ref \\
\hline & Female & 1119 & $27.0 \%$ & $1.08(0.85,1.37)$ & $35.6 \%$ & $1.03(0.82,1.29)$ & $40.3 \%$ & $1.00(0.80,1.25)$ \\
\hline & Social deprivation & & & & & & & \\
\hline & I (Least deprived) & 291 & $28.2 \%$ & Ref & $34.7 \%$ & Ref & $40.0 \%$ & Ref \\
\hline & $\|$ & 318 & $25.8 \%$ & $0.91(0.62,1.34)$ & $35.5 \%$ & $1.09(0.75,1.56)$ & $39.6 \%$ & $1.02(0.71,1.47)$ \\
\hline & III & 366 & $26.0 \%$ & $0.99(0.69,1.44)$ & $36.3 \%$ & $1.24(0.88,1.76)$ & $41.5 \%$ & $1.25(0.88,1.77)$ \\
\hline & IV & 355 & $27.0 \%$ & $1.10(0.76,1.59)$ & $34.9 \%$ & $1.19(0.83,1.69)$ & $39.4 \%$ & $1.13(0.80,1.61)$ \\
\hline & V (Most deprived) & 369 & $27.4 \%$ & $1.09(0.75,1.58)$ & $36.9 \%$ & $1.32(0.93,1.87)$ & $42.5 \%$ & $1.32(0.93,1.88)$ \\
\hline
\end{tabular}

Ref $=$ Reference category. Bold font denotes significance at the $5 \%$ level

Gender for 1 case was not recorded for AMI. No WIMD score was available for $3.2 \%$ of AMI cases, $2.4 \%$ of stroke cases or $3.1 \%$ of SAH cases

a denotes significance after applying a Bonferroni correction

${ }^{b}$ The OR for sex gender is adjusted for age group and comorbidities. All other factors were adjusted for age group, gender and comorbidities 
SAH was 9.2, 11.6 and $26.9 \%$ and at 365 days it was 24.6, 37.7 and $40.4 \%$ respectively.

Social deprivation was significantly associated with higher mortality at 30 days for AMI (deprivation quintile V $=25 \%$ (95\% CI $=12 \%, 40 \%$, when compared with quintile I), stroke $(\mathrm{V}=24 \%$; $14 \%, 34 \%$; III $=12 \% ; 4 \%, 22 \%$ and II $=$ $9 \% ; 0 \%, 19 \%)$ and there was a non-significant increase for SAH (V = $32 \% ;-7 \%, 87 \%$ - see Table 1$)$. There was also a significant association between social deprivation and mortality at 7 days for AMI (deprivation quintile IV $=23 \%$; $7 \%, 40 \%$ and $V=34 \% ; 17 \%, 53 \%)$, stroke (V=17\%; $5 \%$, $30 \%)$ and there was a non-significant increase for $\mathrm{SAH}$ (V $=9 \% ;-25 \%, 58 \%$ - see Table 1 ).

Table 2 shows the numbers of admissions and 30 day mortality rates for each condition and the least and most deprived quintiles ( $\mathrm{I}$ and $\mathrm{V}$ ) of patients according to each study each risk factors. For the majority of factors there was a higher 30 day mortality rate for the most deprived quintile compared to the most affluent quintile. The only exceptions were dementia, public holidays, winter and spring admissions and admissions to medium sized hospitals in AMI cases, COPD, diabetes, renal failure, male gender and community hospitals in stroke cases and asthma, diabetes, dementia, female gender, spring admissions and admissions during 2004-05 and 2009-11 for SAH. The data for all five deprivation quintiles can be found as an Additional file 1.

\section{Effect of risk factors on the relationship between mortality and social deprivation \\ Patient demographics}

The higher mortality among the most deprived quintile of patients $\mathrm{V}$, compared with the least deprived quintile I, was most pronounced among patients aged "75-84y" admitted for AMI (32\%; $9 \%$, $59 \%$ ), and stroke (30\%; $13 \%, 50 \%)$, and among the $85 \mathrm{y}+$ group for $\mathrm{SAH}$ (138 \%; -49 \%, 1004 \% - see Table 3). However, when interaction effects on mortality between social deprivation and age group were assessed, they were significant only for AMI $(p=0.035)$.

Mortality for deprivation quintile V compared with I was highest among females for AMI (26 \%; 7 \%, $49 \%$ ) and stroke (36 \%; $21 \%, 52 \%)$ and among males for AMI (21 \%; 3 \%, $42 \%)$ and SAH (145\%; $21 \%, 395 \%$ - see Table 3) but there were no significant interactions between gender and deprivation on mortality.

\section{Timing of admission}

Although mortality for deprivation quintile $\mathrm{V}$ versus I was highest for weekday admissions for AMI (27\%; $11 \%, 45 \%)$ and stroke (27 \%; $15 \%, 40 \%)$, there were no significant interactions on mortality between week day of admission and social deprivation for SAH. Deprivation inequalities in mortality were highest for admissions during the autumn for both AMI (57 \%; $23 \%, 101 \%$ ) and stroke (36 \%; 14 \%, $62 \%$ - see Table 3) but there was no significant variation in mortality across seasons.

When analysing deprivation-related mortality over time, there was no clear trend for AMI, with inequalities in 2004-2005 and 2009-2011 of $25 \%$ (2\%, $53 \%$ ) and $32 \%$ (7 \%, $63 \%)$ respectively; see Table 3), or for stroke (31 \%; $10 \%, 55 \%$ in 2004-2005 and $21 \% ; 5 \%, 40 \%$ in 2009-2011). For SAH, there was significantly higher mortality in deprived cases for 2006-2008 (3.54 fold) which was significant $(p=0.036)$.

\section{Hospital size}

There was no significant variation in social inequalities in mortality among quintile $\mathrm{V}$ versus $\mathrm{I}$ according to the size of the admitting hospital for any of the three conditions (Table 3).

\section{First admissions and their effect on mortality with social deprivation}

When confining the study to first admissions for AMI, stroke and SAH during the study period, we excluded $1.3 \%$ of AMI cases, $3.8 \%$ of stroke cases and $0.3 \%$ of $\mathrm{SAH}$ cases. The mortality rates at 30 days were unchanged at 14.3, 21.4 and $35.6 \%$ respectively and for 7 days were marginally lower at 9.1, 11.5 and $26.9 \%$. There were no changes to the significance of the interaction effects on mortality between social deprivation and any of the study factors.

\section{Discussion}

We found that social deprivation was significantly associated with higher mortality following admissions for AMI and stroke and, although not significantly, for $\mathrm{SAH}$. We also found that the higher mortality at 30 days with increased social deprivation varied significantly according to patient age for AMI patients and time period for SAH. It was also highest for both AMI and stroke patients, although not significantly, for female patients, for admissions on weekdays and during autumn months.

Major strengths of the study are its size, covering more than 30,000 cases of AMI, almost 38,000 cases of stroke and over 1700 cases of SAH. The methodology was based on systematic, validated record linkage of inpatient, death certificate and primary care data to identify all admissions and all deaths that occur during the impatient stay and following discharge from hospital.

As with other large-scale studies that used NHS administrative health data, this study lacked detailed information about stroke severity, patient disease history, treatment allocated and time to treatment. Our study investigated post-hospital mortality for AMI, stroke and $\mathrm{SAH}$, so did not include deaths that occurred rapidly before admission to hospital. 
Table 2 Admissions and 30 day mortality rates split by risk factors and social deprivation quintiles

\begin{tabular}{|c|c|c|c|c|c|c|}
\hline \multirow[t]{3}{*}{ Risk factors } & \multirow{2}{*}{\multicolumn{2}{|c|}{$\begin{array}{l}\text { AMI } \\
\text { Admissions, \% } 30 \text { days } \\
\text { mortality }\end{array}$}} & \multirow{2}{*}{\multicolumn{2}{|c|}{$\begin{array}{l}\text { Stroke } \\
\text { Admissions, \% } 30 \text { days } \\
\text { mortality }\end{array}$}} & \multirow{2}{*}{\multicolumn{2}{|c|}{$\begin{array}{l}\text { SAH } \\
\text { Admissions, \% } 30 \text { days } \\
\text { mortality }\end{array}$}} \\
\hline & & & & & & \\
\hline & । & V & । & V & I & V \\
\hline \multicolumn{7}{|l|}{ Comorbidities } \\
\hline Ischaemic heart disease (120-125) & $4776,14.5 \%$ & $6342,15.0 \%$ & $1873,23.8 \%$ & $2726,23.3 \%$ & $35,45.7 \%$ & $83,45.8 \%$ \\
\hline Other cardiovascular diseases (100-115, |26-152) & $3702,16.0 \%$ & $4887,16.3 \%$ & $5088,20.3 \%$ & $6273,21.8 \%$ & $161,39.1 \%$ & $197,41.1 \%$ \\
\hline Cerebrovascular disease (160-169) & $521,18.4 \%$ & $733,24.0 \%$ & $6390,20.9 \%$ & $7886,22.0 \%$ & $291,34.7 \%$ & $369,36.9 \%$ \\
\hline Other circulatory diseases (170-199) & $1391,15.0 \%$ & $1827,17.0 \%$ & $2289,18.0 \%$ & $2780,19.2 \%$ & $69,36.2 \%$ & $88,36.4 \%$ \\
\hline Malignancies (C00-C97) & $634,18.6 \%$ & $661,19.5 \%$ & $986,21.8 \%$ & $998,24.4 \%$ & $22,36.4 \%$ & $21,47.6 \%$ \\
\hline Chronic obstructive pulmonary disease (J40-J44) & $511,17.6 \%$ & $1271,18.7 \%$ & $581,22.2 \%$ & $1433,21.1 \%$ & $20,40.0 \%$ & $43,44.2 \%$ \\
\hline Asthma (J45-J46), & $470,12.3 \%$ & $864,13.5 \%$ & $548,17.9 \%$ & $994,18.2 \%$ & $25,44.0 \%$ & $53,30.2 \%$ \\
\hline Diabetes (E10-E14) & $912,16.1 \%$ & $1492,17.4 \%$ & $1089,22.4 \%$ & $1857,19.8 \%$ & $17,52.9 \%$ & $35,45.7 \%$ \\
\hline Dementia (F00-F03, F05.1, G30) & $215,29.8 \%$ & $318,28.6 \%$ & $686,25.1 \%$ & $945,25.9 \%$ & $6,66.7 \%$ & $12,33.3 \%$ \\
\hline Liver disease (K70-K77) & $64,10.9 \%$ & $99,22.2 \%$ & $101,20.8 \%$ & $201,23.4 \%$ & $6,50.0 \%$ & $4,50.0 \%$ \\
\hline Renal failure (N17-N19) & $628,25.2 \%$ & $830,25.8 \%$ & $608,27.3 \%$ & $824,25.6 \%$ & $13,61.5 \%$ & $13,69.2 \%$ \\
\hline \multicolumn{7}{|l|}{ Age } \\
\hline$<65 y$ & $1324,3.6 \%$ & $2307,4.9 \%$ & $871,11.1 \%$ & $1791,11.4 \%$ & $166,28.3 \%$ & $228,28.1 \%$ \\
\hline $65-74 y$ & $1019,10.2 \%$ & $1465,13.4 \%$ & $1250,12.8 \%$ & $1800,15.2 \%$ & $52,34.6 \%$ & $65,41.5 \%$ \\
\hline $75-84 y$ & $1428,17.6 \%$ & $1576,22.1 \%$ & $2357,19.9 \%$ & $2587,24.8 \%$ & $54,50.0 \%$ & $45,57.8 \%$ \\
\hline $85+y$ & $1005,28.9 \%$ & $994,29.8 \%$ & $1912,31.7 \%$ & $1708,36.1 \%$ & $19,47.4 \%$ & $31,61.3 \%$ \\
\hline \multicolumn{7}{|l|}{ Gender } \\
\hline Male & $2976,12.3 \%$ & $3680,12.3 \%$ & 2996, $18.1 \%$ & $3761,17.5 \%$ & $100,30.0 \%$ & $131,41.2 \%$ \\
\hline Female & $1800,18.2 \%$ & $2662,18.9 \%$ & $3394,23.4 \%$ & $4125,26.1 \%$ & $191,37.2 \%$ & $238,34.5 \%$ \\
\hline \multicolumn{7}{|l|}{ Day type } \\
\hline Weekdays (Mon-Fri) & $3493,14.5 \%$ & $4617,15.4 \%$ & $4829,20.3 \%$ & $5814,21.7 \%$ & $213,33.8 \%$ & $267,33.3 \%$ \\
\hline Weekends (Sat-Sun) & $1182,13.8 \%$ & $1600,14.1 \%$ & $1456,22.7 \%$ & $1913,23.0 \%$ & $74,37.8 \%$ & $98,45.9 \%$ \\
\hline Public holidays & $101,22.8 \%$ & $125,14.4 \%$ & $105,21.0 \%$ & $159,22.0 \%$ & $4,25.0 \%$ & $4,50.0 \%$ \\
\hline \multicolumn{7}{|l|}{ Season } \\
\hline Winter & $1231,15.5 \%$ & $1673,15.1 \%$ & 1607, $23.1 \%$ & 1967, $23.0 \%$ & $77,35.1 \%$ & $83,36.1 \%$ \\
\hline Spring & $1293,16.9 \%$ & $1585,15.0 \%$ & $1601,20.8 \%$ & $2063,22.4 \%$ & $70,37.1 \%$ & $95,31.6 \%$ \\
\hline Summer & $1125,13.1 \%$ & $1530,15.0 \%$ & $1584,19.3 \%$ & 1974, $20.4 \%$ & $70,27.1 \%$ & $100,38.0 \%$ \\
\hline Autumn & $1127,12.2 \%$ & $1554,15.1 \%$ & $1598,20.3 \%$ & $1882,22.3 \%$ & $74,39.2 \%$ & $91,41.8 \%$ \\
\hline \multicolumn{7}{|l|}{ Year group } \\
\hline 2004-2005 & $1382,16.4 \%$ & $1838,16.9 \%$ & $1562,20.8 \%$ & $2062,23.3 \%$ & $69,40.6 \%$ & $114,33.3 \%$ \\
\hline 2006-2008 & $1798,15.2 \%$ & $2432,15.1 \%$ & $2353,22.2 \%$ & $3006,22.6 \%$ & $112,29.5 \%$ & $132,45.5 \%$ \\
\hline 2009-2011 & $1596,12.1 \%$ & $2072,13.4 \%$ & $2475,19.7 \%$ & $2818,20.5 \%$ & $110,36.4 \%$ & $123,30.9 \%$ \\
\hline \multicolumn{7}{|l|}{ Hospital size } \\
\hline Small (100-399 beds) & $277,11.9 \%$ & $853,16.5 \%$ & $288,19.4 \%$ & $859,21.9 \%$ & $10,30.0 \%$ & $27,44.4 \%$ \\
\hline Medium (400-599 beds) & $2133,15.1 \%$ & $3400,14.3 \%$ & $2961,21.3 \%$ & $4271,22.9 \%$ & $102,39.2 \%$ & $184,38.6 \%$ \\
\hline Large (600+ beds) & $2102,14.4 \%$ & $1867,15.4 \%$ & $2772,21.7 \%$ & $2335,22.4 \%$ & $173,33.5 \%$ & $147,36.1 \%$ \\
\hline Community hospitals & $264,14.0 \%$ & $222,17.1 \%$ & $369,12.2 \%$ & $421,11.2 \%$ & $6,0.0 \%$ & $11,0.0 \%$ \\
\hline
\end{tabular}

Our 30 day mortality rates were comparable with those reported by other NHS-based studies for AMI [28-30], stroke [1, 31, 32] and SAH [31-33]. The significant association between 30 day mortality and deprivation were also consistent with other similar studies of these conditions in the UK $[2,3,6-8,22,23,34,35]$. 
Table 3 Mortality rates and adjusted odds ratios at 30 days following hospitalisation for social deprivation quintiles I and V, 2004 to 2012

\begin{tabular}{|c|c|c|c|c|c|c|c|c|c|}
\hline \multirow[t]{2}{*}{ Risk factor } & \multicolumn{3}{|l|}{ AMI } & \multicolumn{3}{|l|}{ Stroke } & \multicolumn{3}{|l|}{$\mathrm{SAH}$} \\
\hline & $\begin{array}{l}\text { Mortality rate } \\
\text { (Quintile I) }\end{array}$ & Mortality rate (Quintile V) & $\begin{array}{l}30 \text { days mortality OR } \\
(95 \% \mathrm{Cl})^{b}\end{array}$ & $\begin{array}{l}\text { Mortality rate } \\
\text { (Quintile I) }\end{array}$ & $\begin{array}{l}\text { Mortality rate } \\
\text { (Quintile V) }\end{array}$ & $\begin{array}{l}30 \text { days mortality OR } \\
(95 \% \mathrm{Cl})^{\mathrm{b}}\end{array}$ & $\begin{array}{l}\text { Mortality rate } \\
\text { (Quintile I) }\end{array}$ & $\begin{array}{l}\text { Mortality rate } \\
\text { (Quintile V) }\end{array}$ & $\begin{array}{l}30 \text { days mortality OR } \\
(95 \% \mathrm{Cl})^{\mathrm{b}}\end{array}$ \\
\hline \multicolumn{10}{|l|}{ Age } \\
\hline$<65 y$ & $3.6 \%$ & $4.9 \%$ & $1.35(0.94,1.94)$ & $11.1 \%$ & $11.4 \%$ & $1.14(0.88,1.49)$ & $28.3 \%$ & $28.1 \%$ & $1.20(0.72,2.02)$ \\
\hline $65-74 y$ & $10.2 \%$ & $13.4 \%$ & $1.28(0.98,1.67)$ & $12.8 \%$ & $15.2 \%$ & $1.22(0.98,1.51)$ & $34.6 \%$ & $41.5 \%$ & $2.03(0.80,5.13)$ \\
\hline $75-84 y$ & $17.6 \%$ & $22.1 \%$ & $1.32^{\mathrm{a}}(1.09,1.59)$ & $19.9 \%$ & $24.8 \%$ & $1.30^{\mathrm{a}}(1.13,1.50)$ & $50.0 \%$ & $57.8 \%$ & $1.33(0.53,3.38)$ \\
\hline $85+y$ & $28.9 \%$ & $29.8 \%$ & $1.06(0.87,1.29$ & $31.7 \%$ & $36.1 \%$ & $1.19(1.03,1.37)$ & $47.4 \%$ & $61.3 \%$ & $2.38(0.51,11.04)$ \\
\hline \multicolumn{10}{|l|}{ Gender } \\
\hline Male & $12.3 \%$ & $12.2 \%$ & $1.21(1.03,1.42)$ & $18.1 \%$ & $17.5 \%$ & $1.11(0.97,1.27)$ & $30.0 \%$ & $41.2 \%$ & $2.45(1.21,4.95)$ \\
\hline Female & $18.2 \%$ & $18.9 \%$ & $1.26(1.07,1.49)$ & $23.4 \%$ & $26.1 \%$ & $1.36^{\mathrm{a}}(1.21,1.52)$ & $37.2 \%$ & $34.5 \%$ & $1.04(0.66,1.65)$ \\
\hline \multicolumn{10}{|l|}{ Day of the week } \\
\hline Weekdays (Mon-Fri) & $14.5 \%$ & $15.4 \%$ & $1.27^{\mathrm{a}}(1.11,1.45)$ & $20.3 \%$ & $21.7 \%$ & $1.27^{\mathrm{a}}(1.15,1.40)$ & $33.8 \%$ & $33.3 \%$ & $1.18(0.77,1.82)$ \\
\hline Weekends (Sat-Sun) & $13.8 \%$ & $14.1 \%$ & $1.21(0.96,1.54)$ & $22.7 \%$ & $23.0 \%$ & $1.16(0.98,1.38)$ & $37.8 \%$ & $45.9 \%$ & $1.96(0.86,4.51)$ \\
\hline Public holidays & $22.8 \%$ & $14.4 \%$ & $0.72(0.32,1.63)$ & $21.0 \%$ & $22.0 \%$ & $1.15(0.59,2.23)$ & $25.0 \%$ & $50.0 \%$ & NA \\
\hline \multicolumn{10}{|l|}{ Season of admission } \\
\hline Winter & $15.5 \%$ & $15.1 \%$ & $1.09(0.87,1.36)$ & $23.1 \%$ & $23.0 \%$ & $1.10(0.93,1.30)$ & $35.1 \%$ & $36.1 \%$ & $0.98(0.42,2.28)$ \\
\hline Spring & $16.9 \%$ & $15.0 \%$ & $1.09(0.87,1.37)$ & $20.8 \%$ & $22.4 \%$ & $1.29(1.09,1.53)$ & $37.1 \%$ & $31.6 \%$ & $0.99(0.43,2.29)$ \\
\hline Summer & $13.1 \%$ & $15.0 \%$ & $1.36(1.07,1.72)$ & $19.3 \%$ & $20.4 \%$ & $1.27(1.06,1.51)$ & $27.1 \%$ & $38.0 \%$ & $2.26(0.97,5.24)$ \\
\hline Autumn & $12.2 \%$ & $15.1 \%$ & $1.57^{\mathrm{a}}(1.23,2.01)$ & $20.3 \%$ & $22.3 \%$ & $1.36^{\mathrm{a}}(1.14,1.62)$ & $39.2 \%$ & $41.8 \%$ & $1.76(0.75,4.09)$ \\
\hline \multicolumn{10}{|l|}{ Year of admission } \\
\hline 2004-2005 & $16.4 \%$ & $16.9 \%$ & $1.25(1.02,1.53)$ & $20.8 \%$ & $23.3 \%$ & $1.31^{\mathrm{a}}(1.10,1.55)$ & $40.6 \%$ & $33.3 \%$ & $0.67(0.27,1.65)$ \\
\hline $2006-2008$ & $15.2 \%$ & $15.1 \%$ & $1.16(0.96,1.39)$ & $22.2 \%$ & $22.6 \%$ & $1.23^{\mathrm{a}}(1.07,1.41)$ & $29.5 \%$ & $45.5 \%$ & $3.54^{\mathrm{a}}(1.77,7.07)$ \\
\hline 2009-2011 & $12.1 \%$ & $13.4 \%$ & $1.32(1.07,1.63)$ & $19.7 \%$ & $20.5 \%$ & $1.21(1.05,1.40)$ & $36.4 \%$ & $30.9 \%$ & $0.75(0.40,1.43)$ \\
\hline \multicolumn{10}{|l|}{ Hospital size } \\
\hline Small (100-399 beds) & $11.9 \%$ & $16.5 \%$ & $1.50(0.96,2.36)$ & $19.4 \%$ & $21.9 \%$ & $1.27(0.89,1.82)$ & $30.0 \%$ & $44.4 \%$ & NA \\
\hline Medium (400-599 beds) & $15.1 \%$ & $14.3 \%$ & $1.11(0.94,1.31)$ & $21.3 \%$ & $22.9 \%$ & $1.25^{\mathrm{a}}(1.11,1.42)$ & $39.2 \%$ & $38.6 \%$ & $1.28(0.72,2.29)$ \\
\hline Large (600+ beds) & $14.2 \%$ & $15.4 \%$ & $1.28(1.06,1.55)$ & $21.7 \%$ & $22.4 \%$ & $1.20(1.04,1.39)$ & $33.5 \%$ & $36.1 \%$ & $1.44(0.84,2.47)$ \\
\hline Community hospitals & $14.0 \%$ & $17.1 \%$ & $1.57(0.92,2.69)$ & $12.2 \%$ & $11.2 \%$ & $1.10(0.69,1.76)$ & $0.0 \%$ & $0.0 \%$ & NA \\
\hline
\end{tabular}

Quintile I was used as the reference group. The ORs of quintile $V$ are reported in the table

Bold font denotes significance at the $5 \%$ level

NA The sample size was too small to perform logistic regression

a denotes significance after applying a Bonferroni correction

${ }^{\mathrm{b}}$ The OR for age group was adjusted for gender and comorbidities; gender was adjusted for age group and comorbidities; all other factors were adjusted for age group, gender and comorbidities 
Although not statistically significant we found indications of increased social inequalities in mortality among older age groups, which has been reported from a study of AMI patients aged over 65y in Scotland [36], whilst another study based in Wales reported no association between deprivation and mortality for males aged 50$59 y$ [3], supportive of our study findings for our male group.

We found highest deprivation-related mortality for admissions in autumn for AMI and stroke and in summer for SAH. However, there was no significant overall interaction effect between season and social deprivation on mortality.

Our study found no significant change over time in deprivation-related mortality for AMI and stroke from 2004-05 to 2009-11 as most of the fixed year groups analysed showed increased mortality in deprived groups. For AMI the difference was $25 \%$ in 2004-05 and $32 \%$ in 2009-11, and for stroke it was 31 and $21 \%$. There was a significantly higher, social inequality in mortality for SAH for 2006-2008 than in the other year groups.

Previous studies have reported a reduced likelihood of receiving appropriate, timely treatment for more deprived cases, and therefore, poorer outcomes for stroke [37] and cardiovascular conditions [38, 39], particularly if patients are older [40]. Deprived patients are also known to be less likely to attend or complete rehabilitation following cardiovascular conditions [40-42], which may negatively impact on outcomes.

Admissions to small hospitals showed the highest social inequality in mortality although this was not significant. This finding is supported by an American study comparing mortality rates in large and small hospitals [43]. In some cases the most severe cases are triaged or transferred to the largest hospitals, which increases mortality risks in these hospitals. However, hospital size should be regarded only as a possible indicator, since there were only four 'large' hospitals in our study population.

When considering the findings of this study it is important to remember that any association between (postcode-based) deprivation and higher mortality can be subject to ecological fallacy - not everyone living in a deprived area is deprived - and that not all deprived people live in deprived areas. Our measure of area social deprivation is a mixed exposure that due to economic segregation is correlated with both individual and area characteristics. Social deprivation refers to problems caused by a general lack of resources and opportunities and not just money. The association between social deprivation and higher mortality is also multifaceted. Patient-based factors could include the person's health and wellbeing, with deprived people more likely to have single and multiple comorbidities compared with more affluent patients [44], reduced resources (car and home ownership), lower education status and higher unemployment. Lower social class is associated with lifestyle factors such as smoking and poorer mental health [45] which can also affect prognosis following AMI, stroke and SAH. As such, a patient's baseline clinical and psychological status may largely contribute to any relationship between social deprivation and mortality. We found that the influence of patient demographics, timing of admission and hospital size on social inequalities in mortality are quite similar for $\mathrm{AMI}$ and stroke.

\section{Conclusions}

To conclude, we have demonstrated a clear association between social deprivation and higher mortality following emergency admission for AMI, stroke and SAH. The study findings also suggest that the influence of patient demographics, timing of admission and hospital size on social deprivation inequalities in mortality are quite similar for AMI and stroke.

\section{Additional file}

\section{Additional file 1: Extended Table 2 showing the number of admissions and $30 \mathrm{~d}$ mortality rates for all five deprivation quintiles.}

\section{Abbreviations}

ALF: Anonymised linking field; AMl: Acute myocardial infarction; AR: Administrative Register; DGH: District General Hospital; ICD-10: International Classification of Diseases tenth revision; MACRAL: Matching Algorithm for Consistent Results in Anonymised Linkage; NHS: National Health Service; ONS: Office of National Statistics; PEDW: Patient Episode Database for Wales; SAH: Subarachnoid haemorrhage; SAIL: Secure Anonymised Information Linkage; WIMD: Welsh Index of Multiple Deprivation.

\section{Competing interests}

The authors declare that they have no competing interests.

\section{Authors' contributions}

KT performed the literature review, analysed the data, interpreted the findings and wrote and edited the manuscript. JGW advised on study design, interpreted the study findings and edited the manuscript. AA programmed and analysed the data, interpreted the study findings and edited the manuscript. SER initiated, designed and led the study, obtained funding, reviewed the literature, supervised the analyses, interpreted the findings and edited the manuscript. All authors approved the final version of the article.

\section{Acknowledgements}

This work was supported by the Wellcome Trust [Grant No: 093564/Z/10/Z]. The views expressed in this paper are those of the authors and not necessarily those of the funding body.

The authors are grateful to the Health Information Research Unit (HIRU), College of Medicine, Swansea University, for preparing and providing access to the project specific linked datasets from the SAIL databank, funded by the National Institute of Social Care and Health Research (NISCHR) of the Welsh Government.

Received: 12 December 2014 Accepted: 1 June 2015

Published online: 18 July 2015

\section{References}

1. Nichols M et al. Cardiovascular disease in Europe: epidemiological update. Eur Heart J. 2013;34(39):3028-34. 
2. Capewell $S$ et al. Age, sex, and social trends in out-of-hospital cardiac deaths in Scotland 1986-95: a retrospective cohort study. Lancet. 2001;358(9289):1213-7.

3. Vescio MF et al. Mortality at ages 50-59 and deprivation at early and late stages of the life course in Wales. J Epidemiol Community Health. 2009;63(1):56-63.

4. Bernheim SM et al. Socioeconomic disparities in outcomes after acute myocardial infarction. Am Heart J. 2007;153(2):313-9.

5. Chang WC et al. Effects of socioeconomic status on mortality after acute myocardial infarction. Am J Med. 2007;120(1):33-9.

6. Morrison C et al. Effect of socioeconomic group on incidence of, management of, and survival after myocardial infarction and coronary death: analysis of community coronary event register. BMJ. 1997;314(7080):541-6.

7. Chen $\mathrm{R}$ et al. Socioeconomic deprivation and survival after stroke: findings from the prospective South london stroke register of 1995 to 2011 . Stroke. 2014;45(1):217-23

8. Macleod MR, Andrews PJ. Effect of deprivation and gender on the incidence and management of acute brain disorders. Intensive Care Med. 2002;28(12):1729-34

9. Macleod MR, Lewis SC, Dennis MS. Effect of deprivation on time to hospital in acute stroke. J Neurol Neurosurg Psychiatry. 2003;74(4):545-6.

10. Jakovljevic D et al. Socioeconomic status and ischemic stroke: The FINMONICA Stroke Register. Stroke. 2001;32(7):1492-8.

11. Kunst $A E$ et al. Socioeconomic inequalities in stroke mortality among middle-aged men: an international overview. European Union Working Group on Socioeconomic Inequalities in Health. Stroke. 1998;29(11):2285-91.

12. Maheswaran R, Elliott P, Strachan DP. Socioeconomic deprivation, ethnicity, and stroke mortality in Greater London and south east England. J Epidemiol Community Health. 1997;51(2):127-31.

13. Ahacic K, Trygged S, Kareholt I. Income and education as predictors of stroke mortality after the survival of a first stroke. Stroke Res Treat. 2012;2012:983145.

14. Jakovljevic D et al. Socioeconomic differences in the incidence, mortality and prognosis of intracerebral hemorrhage in Finnish Adult Population. The FINMONICA Stroke Register. Neuroepidemiology. 2001;20(2):85-90.

15. Hawkins NM et al. The UK National Health Service: delivering equitable treatment across the spectrum of coronary disease. Circ Cardiovasc Qual Outcomes. 2013;6(2):208-16.

16. Picciotto $\mathrm{S}$ et al. Associations of area based deprivation status and individual educational attainment with incidence, treatment, and prognosis of first coronary event in Rome, Italy. J Epidemiol Community Health. 2006;60(1):37-43.

17. Fournier $\mathrm{S}$ et al. Influence of socioeconomic factors on delays, management and outcome amongst patients with acute myocardial infarction undergoing primary percutaneous coronary intervention. Swiss Med Wkly. 2013;143:w13817.

18. Weir NU et al. Study of the relationship between social deprivation and outcome after stroke. Stroke. 2005;36(4):815-9.

19. Wong $\mathrm{KY}$ et al. Effect of social deprivation on mortality and the duration of hospital stay after a stroke. Cerebrovasc Dis. 2006;22(4):251-7.

20. Aslanyan $\mathrm{S}$ et al. Effect of area-based deprivation on the severity, subtype, and outcome of ischemic stroke. Stroke. 2003;34(11):2623-8.

21. Barakat $\mathrm{K}$ et al. Socioeconomic differentials in recurrent ischaemia and mortality after acute myocardial infarction. Heart. 2001;85(4):390-4.

22. Davies CA, Leyland AH. Trends and inequalities in short-term acute myocardial infarction case fatality in Scotland, 1988-2004. Popul Health Metr. 2010;8:33.

23. Uren $Z$ and Fitzpatrick J. Geographic variations in health (DS No. 16) Chapter 11. Office of National Statistics; 2001. London: The Stationary Office p. 325-38. http://www.ons.gov.uk/ons/rel/subnational-health3/geographicvariations-in-health-ds-no-16-/2001/index.html

24. Ford DV et al. The SAIL Databank: building a national architecture for e-health research and evaluation. BMC Health Serv Res. 2009;9:157.

25. Lyons RA et al. The SAIL databank: linking multiple health and social care datasets. BMC Med Inform Decis Mak. 2009:9:3.

26. Welsh Assembly Government. Welsh Index of Multiple Deprivation 2008. Cardiff. Welsh Government; 2008. http://gov.wales/docs/statistics/2008/ 080609wimd2008leafleten.pdf
27. Roberts SE et al. Mortality following acute pancreatitis: social deprivation, hospital size and time of admission: record linkage study. BMC Gastroenterol. 2014;14:153.

28. Gale CP et al. Age-dependent inequalities in improvements in mortality occur early after acute myocardial infarction in 478,242 patients in the Myocardial Ischaemia National Audit Project (MINAP) registry. Int J Cardiol. 2013;168(2):881-7.

29. Chung SC et al. Acute myocardial infarction: a comparison of short-term survival in national outcome registries in Sweden and the UK. Lancet. 2014;383(9925):1305-12.

30. Smolina K et al. Incidence and 30-day case fatality for acute myocardial infarction in England in 2010: national-linked database study. Eur J Public Health. 2012;22(6):848-53.

31. Bamford J et al. A prospective study of acute cerebrovascular disease in the community: the Oxfordshire Community Stroke Project-1981-86. 2. Incidence, case fatality rates and overall outcome at one year of cerebral infarction, primary intracerebral and subarachnoid haemorrhage. J Neurol Neurosurg Psychiatry. 1990;53(1):16-22.

32. Syme PD et al. Community-based stroke incidence in a Scottish population: the Scottish Borders Stroke Study. Stroke. 2005;36(9):1837-43.

33. Pobereskin LH. Incidence and outcome of subarachnoid haemorrhage: a retrospective population based study. J Neurol Neurosurg Psychiatry. 2001;70(3):340-3.

34. Lovelock CE, Rinkel GJ, Rothwell PM. Time trends in outcome of subarachnoid hemorrhage: Population-based study and systematic review. Neurology. 2010;74(19):1494-501.

35. Macpherson $\mathrm{KJ}$ et al. Trends in incidence and in short term survival following a subarachnoid haemorrhage in Scotland, 1986-2005: a retrospective cohort study. BMC Neurol. 2011;11:38.

36. Macintyre $\mathrm{K}$ et al. Relation between socioeconomic deprivation and death from a first myocardial infarction in Scotland: population based analysis. BMJ. 2001;322(7295):1152-3.

37. Lazzarino Al et al. Inequalities in stroke patients' management in English public hospitals: a survey on 200,000 patients. PLoS One. 2011;6(3), e17219.

38. Taylor FC et al. Socioeconomic deprivation is a predictor of poor postoperative cardiovascular outcomes in patients undergoing coronary artery bypass grafting. Heart. 2003;89(9):1062-6.

39. MacLeod MC et al. Geographic, demographic, and socioeconomic variations in the investigation and management of coronary heart disease in Scotland. Heart. 1999;81(3):252-6.

40. Melville MR et al. Cardiac rehabilitation: socially deprived patients are less likely to attend but patients ineligible for thrombolysis are less likely to be invited. Heart. 1999;82(3):373-7.

41. Pell $\mathrm{J}$ et al. Retrospective study of influence of deprivation on uptake of cardiac rehabilitation. BMJ. 1996;313(7052):267-8.

42. Hippisley-Cox J, Pringle M. Inequalities in access to coronary angiography and revascularisation: the association of deprivation and location of primary care services. Br J Gen Pract. 2000;50(455):449-54.

43. Fareed N. Size matters: a meta-analysis on the impact of hospital size on patient mortality. Int J Evid Based Healthc. 2012;10(2):103-11.

44. Charlton J et al. Impact of deprivation on occurrence, outcomes and health care costs of people with multiple morbidity. J Health Serv Res Policy. 2013;18(4):215-23.

45. Fone DL, Dunstan F. Mental health, places and people: a multilevel analysis of economic inactivity and social deprivation. Health Place. 2006;12(3):332-44.

\section{Submit your next manuscript to BioMed Central and take full advantage of:}

- Convenient online submission

- Thorough peer review

- No space constraints or color figure charges

- Immediate publication on acceptance

- Inclusion in PubMed, CAS, Scopus and Google Scholar

- Research which is freely available for redistribution 